Cad.Est.Ling., Campinas, (44):251-261, Jan./Jun. 2003

\title{
DEPOIS DO 'SHOW', COMO ENCONTRAR ENCANTAMENTO?
}

\author{
JOÃO WANDERLEY GERALDI \\ (UNICAMP)
}

\begin{abstract}
A vida é um tecido misturado ou alternativo de prosa $e$ poesia. Pode-se chamar prosa às actividades práticas, técnicas e materiais que são necessárias à existência. Pode-se chamar poesia ao que nos põe num estado segundo: primeiro a própria poesia, depois a música, a dança, o regozijo e, bem entendido, o amor.
\end{abstract}

(Edgar Morin)

\begin{abstract}
This article assumes the point of view that we are now able to develop a different way of learning, grounded on the discoursive aspects of language and taking reading activities as the most important motivation for this task.
\end{abstract}

\section{FERIDAS, PROMESSAS E DESENCANTOS}

Não deve ter sido sem traumas e sem desencantos que o homem medieval se deparou com o primeiro golpe que lhe deu a modernidade: saber-se habitante de um planeta que, por força das novas compreensões do mundo, deixava de ser o centro do universo, rodando em torno do sol como se fora um astro qualquer. Terra, maravilha da divina bondade, mas sem qualquer lugar de proeminência. Brincadeira do criador com suas criaturas? Ou talvez o desencanto maior de uma origem física, pouco divina. Não faltaram vontades e fogueiras para repelir o ataque, evitar a sangrenta ferida e manter as verdades tão ingênuas dos rebanhos da fé.

Com pouco tempo para cicatrizar a ferida da brincadeira de mau gosto do criador em nos fazer habitar um planeta tão marginal, as criaturas se crendo criadas recebem novo golpe: sem qualquer "à imagem e semelhança" de outro existente no além, nos sabemos resultado de acasos, erros e acertos de uma evolução das espécies. A origem divina recebe seu golpe de misericórdia. Somos mais humanos, bem mais humanos do que nossa imaginação gostaria. Não faltaram proibições à divulgação de idéias tão nefastas. Se não há de onde se veio, também pode não haver para onde ir. Restaria a vida e seu tempo? Seria um tempo de reduzi-la ao desenho matemático de compreensão do jogo material de causas e efeitos? 
Perda da origem, ferida ainda incurável, e eis que compreendemos que não somos racionalidades perfeitas: sob o tapete do consciente, escondem-se paixões, pulsões, recalques, mundos que a razão qualificaria de tenebrosos. E o inconsciente conduz também nossas ações, a construção de nossos objetos, de nossas relações e de nossas compreensões supostas apenas racionais. Mais uma vez não faltaram reações. $\mathrm{Na}$ ausência das fogueiras e das proibições, mais sutis se fizeram as formas de controle dos discursos e das possibilidades de emergência do que subjaz ao consciente: escutas atentas em busca de formas de cura ou do retorno às normalidades. Afinal,

\begin{abstract}
... ser racional não seria compreender os limites da racionalidade e da parte de mistério do mundo? A racionalidade é um utensílio maravilhoso, mas existem coisas que excedem o espírito humano. A vida é um misto de irracionável e de racionalidade. Seria preciso aprender, de algum modo, a jogar de forma lúdica com esta parte irracional das nossas vidas e saber aceitá-la. Confesso que, quando estou só na floresta à noite, tenho medo, não dos bandidos, mas dos fantasmas! Sei que é um medo irracional, mas, ao mesmo tempo, sei que não o posso reprimir. (Morin, E. 1997, p.60)
\end{abstract}

Copérnico e Galileu, Darwin e Freud. Cada um a seu tempo, cada um com seu bisturi. Mas não só de feridas se fez o homem moderno. A modernidade, ao nos subtrair o mistério, ao nos retirar o encantamento e do encantamento, prometeu-nos muito e nos deu muito a partir da ciência. São inegáveis conquistas: a confiança nas leis científicas, o que nos permite, por exemplo, sem ficarmos alucinados, imaginar-nos parados sabendo que estamos em movimento, quase vertiginoso, certos de que a gravidade continuará nos mantendo sobre o curvo que enxergamos plano; as certezas em nossos cálculos que encorajam viagens no planeta e para fora dele; o prolongamento da vida facilitado pela bioquímica, pela genética e pela tecnologia médica; as facilidades tecnológicas do cotidiano, rodeado de máquinas com botões e interruptores sem os quais, hoje, não saberíamos viver; as velocidades no locomover-se e no comunicar-se, navegadores internautas virtualmente sem limites.

Para tanto, a modernidade fez do homem e do mundo objetos que esquadrinhou, dissecou, mensurou. E apresentou suas descrições aos homens crédulos e atônitos que, sentados nos sofás, tomaram conhecimento do fantástico reduzido a fórmulas e explicações. Já não havia mais segredos. Fez-se o show da ciência: leis universais, objetivas: futuro desvendado.

\title{
MOMENTO NUM CAFÉ
}

\section{Manuel Bandeira}

Quando o enterro passou

Os homens que se achavam no café

Tiraram o chapéu maquinalmente

Saudavam o morto distraídos

Estavam todos voltados para a vida

Absortos na vida

Confiantes na vida. 
Um no entanto se descobriu num gesto largo e demorado

Olhando o esquife longamente

Este sabia que a vida é uma agitação feroz e sem finalidade

Que a vida é traição

E saudava a matéria que passava

Liberta para sempre da alma extinta.

$\mathrm{Na}$ consciência de que somos humanos, demasiadamente humanos, com a alma extinta na matéria que passa, encerrada a confiança no criador, confiávamos nas respostas da ciência moderna. E eis que ela nos ofereceu os primeiros 'shows' como tragédia: nenhuma relevância para o planeta que habitamos; depois, nenhuma origem que dê conta do nosso olhar narcisista e superior; enfim, nenhuma certeza na racionalidade que nos envolve como manto a esconder nossas incuráveis feridas. Os desencantos, no entanto, construíram outras âncoras para nossas confianças: as certezas de que conheceríamos tudo, a tudo descreveríamos, a tudo compreenderíamos. Domínio da natureza pelo conhecimento, domínio do homem pela racionalidade: perdido o encanto, ganharíamos em poder de compreensão, explicitação e deslindamento de qualquer mistério. Eis nos diante do destino inexorável das leis da natureza. Restaria regular as apropriações humanas dos resultados: tornar de todos o que o poder torna de poucos. Questão de tempo, questão de história. Para outros, questão de luta.

Para tornar concreta a promessa, explicar a vida pela ciência e viver a vida segundo a ciência, também as ciências humanas foram 'matematicizando-se', construindo seus objetos científicos e desligando-se das interpretações dependentes do sujeito. Ao mesmo tempo, o avanço das ciências ditas duras, exatas, caminhava no sentido da desconstrução das três características básicas que as introduziram como substitutas dos objetos de nossas crenças: universalidade, objetividade e preditibilidade.

Acompanhando Santos (1987: 24-28), pode-se dizer que a universalidade é posta em questão pela teoria da relatividade na física, já que esta reincluiu as questões do tempo e do espaço; a objetividade é posta em questão pelas observações de Heisenberg e Bohr, já que as medições mais precisas de um objeto não ocorrem sem que nele se interfira com os instrumentos utilizados; a preditibilidade é posta em questão pela teoria das estruturas dissipativas de Prigogine. Chegamos

... a uma nova concepção da matéria e da natureza que propõe uma concepção dificilmente compaginável com a que herdámos da física clássica. Em vez da eternidade, a história; em vez do determinismo, a imprevisibilidade; em vez do mecanicismo, a interpenetração, a espontaneidade e a auto-organização; em vez da reversibilidade, a irreversibilidade e a evolução; em vez da ordem, a desordem; em vez da necessidade, a criatividade e o acidente.

Concluído o show possível, já não restam certezas. Há acasos e possibilidades:

\section{José}

Carlos Drummond de Andrade

E agora, José?

A festa acabou,

a luz apagou, 
o povo sumiu,

a noite esfriou,

e agora José?

e agora, você?

você que é sem nome

que zomba dos outros, você que faz versos, que ama, protesta?

e agora, José?

Está sem mulher, está sem discurso, está sem carinho, já não pode beber, já não pode fumar, cuspir já não pode, a noite esfriou,

o dia não veio,

o bonde não veio, o riso não veio, não veio a utopia e tudo acabou e tudo fugiu e tudo mofou, e agora, José?

E agora, José?

Sua doce palavra, seu instante de febre, sua gula e jejum, sua biblioteca, sua lavra de outro, seu terno de vidro, sua incoerência, seu ódio - e agora?

Com a chave na mão quer abrir a porta, não existe porta; quer morrer no mar, mas o mar secou; quer ir para Minas, Minas não há mais. José, e agora?

Se você gritasse, se você gemesse, se você tocasse a valsa vienense, se você dormisse, se você cansasse, se você morresse Mas você não morre você é duro, José! 

Sozinho no escuro
qual bicho-do-mato,
sem teogonia,
sem parede nua
para se encostar,
sem cavalo preto
que fuja a galope,
você marcha, José!
José, para onde?

Que nos trazem os tempos atuais para além das dúvidas, incertezas e desencantos? Fechado o pano, concluído o show da ciência moderna, que nos resta?

\title{
2. OS PARADOXOS DESTA NOVA LIBERDADE
}

Libertados do jugo do senhor, apostamos nossas potencialidades - esquecendo algumas, obviamente - nas possibilidades de uma compreensão objetiva das realidades. Libertados agora dos destinos, supostos inexoráveis, dos modos de funcionamento da natureza, resta-nos uma paradoxal liberdade:

\begin{abstract}
A liberdade é o outro lado do limite, da linha, supera todas as condições de determinação impostas pela episteme, escapa a todos os determinismos, e por isso deve permanecer como algo radical e absolutamente incognoscível, e por isso devemos respeitar sua irredutibilidade à compreensão. [...] no sentido em que sujeito significa "sujeição", no sentido em que ser um sujeito implica estar submetido a determinismos, a liberdade elimina a sujeição.

Mas este "jogo de palavras" não pode apagar a pergunta fundamental neste terreno: esta concepção de liberdade determina ou pressupõe a existência de um sujeito livre? Não é suficiente dizer de que a liberdade nos liberta, é necessário dizer para que nos faz livres. Faznos livres para nos darmos uma lei. Para inventá-la de forma totalmente não condicionada: é precisamente isso o que significa que tudo é permitido - muito mais um convite à moderação ou à modulação, e não à libertinagem ou à barbárie. A liberdade, para dizê-lo numa clave sartreana, nos condena a darmo-nos uma lei (mas não nos diz que lei temos que nos darmos). A lei que nos damos pressupõe a liberdade, mas uma liberdade que não é nossa, da que não somos donos, uma liberdade que somente se converte em nossa liberdade quando efetivamente nos damos uma lei, uma liberdade de que nos apropriamos inventando uma lei. (Pardo, 1996a: 152153)
\end{abstract}

A lei que temos a liberdade de nos darmos, no entanto, ao longo da modernidade, tornou-se um conjunto emaranhado de normas de tal modo que a cada momento devemos estar em conformidade com alguma destas normas. Como mostrou Foucault, as teias com que se tecem as relações sociais estão marcadas não pela decisão de regulamentações que nos tornem livres, mas pelo exercício do poder de modo a sujeitar para manter desigualdades como se estas fossem da natureza da coabitação da terra por sujeitos historicamente diferentes. A este círculo, que isola o indivíduo em sua relação com a sociedade como um todo, dedicaram-se inúmeros estudos sobre o poder e sobre as reproduções de suas relações.

Aqueles que nos são próximos, iguais a nós em direitos, constituem outro círculo que se fecha em torno de nossa liberdade: porque sou igual, será necessário de que 
alguma forma me singularize, afastando-me do que me é próximo, sem contudo tomar demasiada distância para não parecer que estou "fora do jogo". Por uma lógica horizontal, é preciso que tome o outro por referência para dele me diferenciar: uns e outros estatuímos modos de regulamentar o cotidiano, onde a diferença singulariza sem distanciar.

Por fim, mas não com menor força, estamos condenados a sermos cada um o herói de sua própria vida: valores morais como a autenticidade, a sinceridade e a adequação consigo próprio exigem comportamentos, ditam modos de ser e exigem que respondamos pelo lugar que ocupamos. Glorificar a própria existência pela coerência consigo próprio, mesmo diante de tarefas impossíveis com que se confronta permanentemente.

Usar o controle remoto para trocar de canais, eis a caricatura desta liberdade vigiada, regulamentada, normalizada, em que nos isolamos numa suposta interioridade de leitores-expectadores condenados a ler o mesmo e sua reprodução nas inúmeras novidades que as programações de televisão oferecem, seja esta novidade a passagem veloz de um fragmento de notícia para outro, deslocando-nos todas as noites pelo mundo sem que dele apreendamos a história de sua construção, seja esta novidade o retorno cada vez mais insistente dos mesmos quadros, das mesmas estruturas, dos mesmos risos sobre os mesmos estereótipos, quase sempre preconceituosos. Na idade da mídia, a relação com o aparelho de tevê talvez seja a melhor síntese do isolamento do sujeito, apertado pelos círculos que o individualizam e que simultaneamente lhe exigem ser regulado, igual aos outros e autêntico.

Esquecemos que as temporalidades constróem diferentes identidades, que a alteridade implica co-cidadania e que nada há que fundamente, internamente ou externamente, uma autonomia absoluta que exija autenticidade e conformidade consigo próprio. Somos mutáveis e mutantes. Construímos diferentes formas de integração social, espaço da regulamentação; podemos manter relações com os outros não ditadas pela lógica horizontal que nos obriga a seguirmos uma moda ou pela lógica vertical que nos obriga a competir para estarmos acima e além da linha da igualdade, que nos parece intolerável; por fim, não somos transparentes, não somos límpidos, não somos e não estamos sempre iguais, ao contrário somos e não somos o que gostaríamos de ser, temos nossas dependências do que é nossa história, do que nos cerca, do que nos faz capazes de responder e assumir um lugar.

A grande nova aprendizagem talvez seja aquela de nos sabermos livres: livres das determinações de um ser supremo e externo a nós próprios; livres dos determinismos da física, da química ou outras quaisquer leis que se pensem exatas.

Em 1911, o Barão Fourrier descobre a lei segundo a qual o fluxo de calor é determinado pelo gradiente da temperatura. Começa por o calor ir do quente para o frio. Esta lei introduz uma orientação temporal, um elemento irreversível, em contradição absoluta com as leis da ciência clássica. [...]

A questão que passa a formular-se é a de saber como conciliar estas duas visões que temos o mundo, uma obedecendo às leis da dinâmica, deterministas, reversíveis no tempo, e outra às leis da termodinâmica, à entropia, ela mesmo referida àquela flecha do tempo que corresponde à evolução do universo. [...] 
O não-equilíbrio dá uma idéia das potencialidades da matéria. Até aqui a matéria era concebida como algo de inerte, de passivo. Em certa medida é verdade quanto ao equilíbrio. Longe do equilíbrio, a matéria torna-se "activa". Explora, sem parar, novas possibilidades. A questão que deve agora ser estudada é a de saber como é que a natureza faz para imprimir o não-equilíbrio à matéria. As estruturas complexas, as novas coerências que se criam longe do equilíbrio, são certamente as únicas susceptíveis de explicar a transição da não-vida para a vida. (Prigogine, 1996: 230-234)

É necessário apontar para os não-equilíbrios sociais para explorar as novas possibilidades de nos darmos regulamentações outras, em que o paradoxo da liberdade individual se complemente pela responsabilidade da co-existência. Experimentar novos caminhos, sem exigir que já estejam prontos antes de serem percorridos é aceitar toda ação como uma aposta.

\footnotetext{
"Vem por aqui" - dizem-me alguns com olhos doces,

Estendendo-me os braços, e seguros

De que seria bom que eu os ouvisse

Quando me dizem: "vem por aqui"!

Eu olho-os com olhos lassos,

(Há, nos meus olhos, ironias e cansaços)

E cruzo os braços,

E nunca vou por ali...

(Cântico Negro, José Régio)
}

\section{LER: RETORNAR ÀS PERGUNTAS, RETORNAR À INTERROGAÇÃO}

Com o poeta aprendemos que a luta com as palavras é vã, e no entanto, como o poeta, quase todos nós passamos os dias diante das letras, que outros traçaram e que nossos olhos acompanham enquanto nossa mente se desloca de um espaço para outro, ou com as letras traçamos nós mesmos linhas em que pretendemos ir deixando vestígios de nosso trabalho constante, incansável. Condenados a significar, por sermos "seres viventes dotados de palavra", estamos sempre às voltas com as palavras e com elas vamos construindo para nós mesmos e para os outros os sentidos do que vemos, tocamos, ouvimos: nos espaços, os homens, as coisas e suas relações são temporalizados pelas linguagens com que interpretamos o que nos acontece.

Abandonadas as certezas, sem âncoras, estamos forçados a pensar sem corrimãos que nos conduzam, porque não há um lugar a que chegar, não há um lugar em que ficar, não há um fim a alcançar. Por isso, talvez devamos retornar às perguntas fundamentais "que deveriam acompanhar-nos sempre como sinal de uma capacidade, essa sim, comum a todos os seres humanos: a capacidade que mantém viva a pergunta precisamente porque, sabendo que não há resposta, obriga-nos a continuar perguntando" (Ferre, 2001, p.206).

Quem sou eu? O que produz em mim a presença do outro? Uma resposta possível: compreender que temos a identidade que os outros nos dão. Mas há no interior mesmo desta identidade socialmente construída, uma intimidade que articula respostas, imposições, significações, incertezas. 
Não tenho intimidade porque eu saiba quem sou, mas porque sou aquele para quem nunca se esgota o sentido da pergunta "Quem sou?", a pergunta menos fundamental do menos fundamental dos saberes (ninguém se atreveria a chamá-lo de ciência), o saber de si mesmo, o saber acerca da falta de saber, acerca da falta de fundamento da própria existência, o saber (o sabor) da intimidade. (Pardo, 1996b: 51)

$\mathrm{Eu}$, reduzida a uma palavra? Mas que palavra me representa? De uma coisa sei: eu não sou o meu nome. O meu nome pertence aos que me chamam. Mas, meu nome íntimo é: zero. É um eterno começo permanentemente interrompido pela minha consciência de começo. (Clarice Lispector, Um Sopro de Vida, p.127)

Talvez seja necessário retornar a estas perguntas, para com elas construir respostas provisórias que nos permitam conviver com a instabilidade, sem reduzi-la ao efêmero da informação tão veloz e constante na modernidade. Se vivemos uma "idade da mídia", talvez tenhamos que construir sobre o mundo uma leitura distinta daquela oferecida pela informação midiática que

mostra em público o rosto de um homem morto, de uma criança faminta, de uma mãe ultrajada, de um suposto delinqüente, de um tetraplégico em sessão de reabilitação, do afortunado ganhador de um prêmio da loteria ou de um ferido em acidente de automóvel, de um espião político, de um informante policial ou de um mendigo, e tudo isso sem pagar um centavo ao sujeito exposto, sem pedir-lhe sequer permissão e sem aceitar as mais mínimas responsabilidades pelas conseqüências que tal divulgação pública possa acarretar, o que seria absolutamente impensável em qualquer outra atividade comercial ou relação jurídica num Estado de direito. (Pardo, 1996b: 15)

Tenho medo de escrever. É tão perigoso. Quem tentou, sabe. Perigo de mexer no que está oculto - e o mundo não está à tona, está oculto em suas raízes submersas em profundidades do mar. Para escrever tenho que me colocar no vazio. Neste vazio é que existo intuitivamente. Mas é um vazio terrivelmente perigoso: dele arranco sangue. Sou um escritor que tem medo da cilada das palavras: as palavras que digo escondem outras - quais? Talvez as diga. Escrever é uma pedra lançada no poço fundo. (Clarice Lispector. Um Sopro de Vida, p.13)

Como pensar uma leitura distinta, entre sujeitos tão diferentes, todos submetidos aos rituais aconchegantes da digestão fácil da informação? Ler para encontrar as palavras que se escondem. Ler para fazer dialogarem palavras que se opõem. Ler sem a pressa do consumo, ler com tempo sabendo que o tempo passa e é inexorável. Ler sem deixar-se levar, mas se permitir embalar pelas palavras.

A linguagem humana não responde apenas a necessidades práticas e utilitárias. Responde às necessidades de comunicação afetiva. A linguagem humana permite dizer palavras gentis. Permite, igualmente, falar por falar, dizer não importa o quê pelo prazer de comunicar com outrem. (Morin, E. 1997: 55)

Talvez seja possível pensar a leitura como uma oferta de contrapalavras do leitor que, acompanhando os traços deixados no texto pelo autor, faz estes traços renascerem pelas significações que o encontro de palavras e contrapalavras produz. 
Para pensar a leitura a partir desta perspectiva, é preciso enfrentar o problema de construir, no fluxo das instabilidades, uma estabilidade, e confessá-la ao Outro como uma posição provisória que permite propor a hipótese. Eis pois esta posição: instaurar a linguagem como um processo de contínua constituição que se produz na precariedade que a temporalidade implica. E se o sujeito emerge no mundo discursivo e nele sua consciência se constitui, a precariedade do provisório é também, pelo funcionamento próprio da linguagem, uma característica da subjetividade. Não há, para nos garantir um terreno estável, nem um sujeito pronto e acabado que se apropria de uma língua supostamente pronta, acabada e transparente. Sobra-nos, neste sentido, apenas o evento discursivo, que se dá na linha do tempo e que só tem consistência enquanto "real" na singularidade do momento. A relação com a singularidade é da natureza do processo constitutivo da linguagem e dos sujeitos do discurso.

Para dar conta desde movimento entre estabilizações e instabilidades, Bakhtin(1929/1981) opõe dois conceitos: aquele de significação e aquele de tema. Se consideramos que uma língua é um conjunto instável de recursos lingüísticos com que construímos representações com "acentos apreciativos" (portanto nunca neutros), cada um destes recursos traz em si "os murmúrios de sua própria história" condensados como suas significações que se apresentam em cada uma de suas reiterações. E nestas reiterações, estes mesmos recursos se desvestem de suas significações para se revestirem com as vestes que lhe traz o tema específico do discurso.

Dada a impossibilidade de prever quais as contrapalavras que virão a este encontro, porque elas comparecem segundo os percursos já percorridos por cada diferente leitor e segundo os inumeráveis momentos da leitura, é impossível prever todos os sentidos que a leitura produz. Por isso, um texto, uma vez nascido, passa a ter histórias que não são a reprodução de sentidos sempre idênticos a si mesmos. E por isso, ler, esta operação de caça,

é peregrinar por um sistema imposto (o do texto, análogo à ordem construída de uma cidade ou de um supermercado). Análises recentes mostram que "toda leitura modifica o seu objeto", que (já dizia Borges) "uma literatura difere de outra menos pelo texto que pela maneira como é lido", e que enfim um sistema de signos verbais ou icônicos é uma reserva de formas que esperam do leitor o seu sentido. ${ }^{1}$ (Certeau, 1994: 264)

Para pensar os diferentes modos de ler, há que se aceitar que toda leitura é sempre diferente de outra leitura, ainda que se repitam textos e leitores. E nesse sentido, é preciso aprofundar a riqueza da diversidade sem cair na insensatez das regras fáceis de que tudo vale, que não há desigualdades a superar, que não há sentidos em circulação e compromissos entre leitores e autores.

Mais do que nunca, quando perdemos as âncoras das certezas teológicas ou científicas, ideológicas ou teóricas, estamos sendo chamados ao exercício da liberdade de nos darmos uma nova lei, em que o sentimento de vivermos uma comunidade de

${ }^{1} \mathrm{O}$ autor remete, em suas notas 8 e 9, às seguintes referências: Michel Charles. Rhétorique de la lecture, Paris, Seuil, 1977, p.83 e Jorge Luís Borges, cit. em Gérard Genette, Figures, Paris, Seuil, 1966, p.123. 
destino permita fazer aparecer os sentimentos vividos de solidariedade e fraternidade, já que "nada é mais pobre que uma verdade sem sentimento de verdade". As verdades, sem sentimentos e sem temporalidades, produziram um mundo cuja globalização em vez de alargar nossos horizontes, fechou-nos em nossos medos e sobressaltos. Quando os futuros são incertos, porque não seguem uma lei ou uma ordem, todas as possibilidades são imagináveis. Abramos os braços para os abraços desta nova aprendizagem.

\section{ELOGIO DO APRENDIZADO}

Bertold Brecht

Aprende o que é mais simples! Para aqueles

cujo momento chegou,

nunca é tarde demais.

Aprende o $\mathrm{ABC}$ : não basta, mas

aprende-o! Não desanimes!

Tens de assumir o comando!

Aprende, homem no refúgio!

Aprende, homem na prisão!

Mulher na cozinha, aprende!

Aprende, sexagenário!

Tens de assumir o comando!

Procura a escola, tu que não tens casa!

Cobre-te de saber, tu que tens frio!

Tu, que tens fome, agarra o livro: é uma arma!

Tens de assumir o comando!

Não tenhas medo de fazer perguntas:

não te deixes levar por convencido,

vê como teus próprios olhos!

O que não sabes por experiência própria,

a bem dizer, não sabes.

Tira a prova da conta:

és tu quem vai pagar!

Aponta o dedo sobre cada item,

pergunta: como foi parar aí?

Tens de assumir o comando!

\section{BIBLIOGRAFIA}

ANDRADE, Carlos Drummond de. (1998). “José” in. Antologia Poética. Rio de Janeiro, Record, 40ª edição, p.20-22

BANDEIRA, Manuel. (2001). "Momento num café" in. Rosa do Mundo. 2001 Poemas para o Futuro. Lisboa, Assírio \& Alvim, p. 1269.

BAKHTIN, Mikhail. (1981). Marxismo e filosofia da linguagem. São Paulo, Hucitec.

BRECHT, Bertold. (1966). "Elogio do aprendizado" in. Poemas e canções. Tradução de Geir Campos, Rio de Janeiro, Civilização Brasileira. 
CERTEAU, Michel. (1994). A invenção do cotidiano. Artes de fazer. Petrópolis, Vozes.

FERRE, Núria Pérez de Lara. (2001). "Identidade, diferença e diversidade: manter viva a pergunta" in. Jorge Larrosa e Carlos Skliar (orgs). Habitantes de Babel. Belo Horizonte, Autêntica, p. 195-214.

FOUCAULT, Michel. (1996). A ordem do discurso. São Paulo, Edições Loyola.

LISPECTOR, Clarice. (1978). Um sopro de vida (Pulsações). Rio de Janeiro, Nova Fronteira, 6 edição.

MORIN, Edgar. Amor, Poesia, Sabedoria. Lisboa, Instituto Piaget, s/data. Original francês de 1997.

PARDO, José Luis. (1996a). "El sujeto inevitable" in. Manuel Cruz (org). Tiempo de Subjetividad. Barcelona, Paidós, p. 133-154. . (1996b). La intimidad. Valencia, Pre-Textos.

PRIGOGINE, Ilya. "O reencantamento do mundo" in. Edgar Morin, Ilya Prigogine et alii. A sociedade em busca de valores. Para fugir à alternativa entre o cepticismo e o dogmatismo. Lisboa, Instituto Piaget, s/data. Original francês de 1996, p. 229-237.

RÉGIO, José. (2001). Antologia Poética. Não vou por aí. Seleção e organização de Isabel Cadete Novais. Vila Nova de Famalicão, Quasi Edições.

SANTOS, Boaventura de Sousa. (1987). Um discurso sobre as ciências. Porto, Afrontamento. 